\title{
Gaps in the hepatitis $C$ continuum of care among sex workers in Vancouver, British Columbia: Implications for voluntary hepatitis $C$ virus testing, treatment and care
}

\author{
M Eugenia Socías $M D^{1,2}$, Kate Shannon PhD MPH ${ }^{1,3,4}$, Julio S Montaner MD ${ }^{1,3}$, Silvia Guillemi MD ${ }^{1,3}$, \\ Sabina Dobrer $\mathrm{MA}^{1}$, Paul Nguyen $\mathrm{PhD}^{1}$, Shira Goldenberg $\mathrm{PhD}^{1,5}$, Kathleen Deering $\mathrm{PhD}^{1,3}$
}

\begin{abstract}
ME Socías, K Shannon, JS Montaner, et al. Gaps in the hepatitis C continuum of care among sex workers in Vancouver, British Columbia: Implications for voluntary hepatitis $\mathrm{C}$ virus testing, treatment and care. Can J Gastroenterol Hepatol 2015;29(8):411-416.
\end{abstract}

BACKGROUND: Hepatitis C virus (HCV) eradication leads to reduced morbidity, mortality and transmission. Despite the disproportionate burden of HCV among sex workers, data regarding the HCV care continuum in this population remain negligible.

METHODS: Using baseline data from an ongoing cohort of women sex workers in Vancouver (An Evaluation of Sex Workers' Health Access, January 2010 to August 2013), the authors assessed HCV prevalence and engagement in the $\mathrm{HCV}$ care continuum within the past year. Multivariable logistic regression analyses were used to evaluate associations with recent (ie, in the past year) HCV testing.

RESULTS: Among 705 sex workers, 302 (42.8\%) were HCV seropositive. Of these, $22.5 \%$ were previously unaware of their HCV status, $41.7 \%$ had accessed HCV-related care, $13.9 \%$ were offered treatment and only $1.0 \%$ received treatment. Among $552 \mathrm{HCV}$ seronegative sex workers, only one-half $(52.9 \%)$ reported a recent HCV test. In multivariable analysis, women who self-identified as a sexual/gender minority (adjusted OR [aOR] 1.89 [95\% CI 1.11 to 3.24]), resided in the inner city drug use epicentre (aOR 3.19 [95\%CI 1.78 to 5.73$]$ ) and used injection ( $\mathrm{aOR} 2.00$ [95\% CI 1.19 to 3.34]) or noninjection drugs (aOR 1.95 [95\% CI 1.00 to 3.78]) had increased odds of undergoing a recent HCV test, while immigrant participants (aOR 0.24 [95\% CI 0.12 to 0.48]) had decreased odds.

CONCLUSIONS: Despite a high burden of HCV among sex workers, large gaps in the HCV care continuum remain. Particularly concerning are the low access to HCV testing, with one-fifth of women living with HCV being previously unaware of their status, and the exceptionally low prevalence of HCV treatment. There is a critical need for further research to better understand and address barriers to engage in the HCV continuum for sex workers.

Key Words: Hepatitis C; HCV testing; HCV treatment; People who use drugs; Sex workers; Women
Les lacunes dans le continuum des soins de l'hépatite $\mathrm{C}$ chez les travailleuses du sexe de Vancouver, en Colombie-Britannique : les conséquences sur les tests volontaires de dépistage, le traitement et les soins de l'hépatite $\mathrm{C}$

HISTORIQUE : L'éradication du virus de l'hépatite C (VHC) entraîne une diminution de la morbidité, de la mortalité et de la transmission de la maladie. Malgré le fardeau disproportionné du VHC chez les travailleuses du sexe, les données relatives au continuum des soins du VHC demeurent négligeables au sein de cette population.

MÉTHODOLOGIE : Au moyen de données initiales provenant d'une cohorte de travailleuses du sexe de Vancouver (une évaluation de l'accès des travailleuses du sexe à la santé, de janvier 2010 à août 2013), les auteurs ont évalué la prévalence du VHC et la participation au continuum des soins du VHC au cours de l'année précédente. Les analyses de régression logistique multivariées ont permis d'évaluer les associations avec les récents tests du VHC (depuis un an).

RÉSULTATS : Des 705 travailleuses du sexe, 302 (42,8 \%) étaient séropositives au VHC. De ce nombre, 22,5\% ne le savaient pas auparavant, $41,7 \%$ avaient eu accès à des soins liés au VHC, 13,9 \% s'étaient fait offrir un traitement et seulement 1,0 \% avait reçu un traitement. Chez les 552 travailleuses du sexe séronégatives au VHC, seulement la moitié $(52,9 \%)$ déclarait avoir récemment subi un test de dépistage. À l'analyse multivariée, celles qui affirmaient faire partie d'une minorité sexuelle ou de genre ( $\mathrm{RC}$ rajusté $[\mathrm{RCr}]$ 1,89 [95 \% IC 1,11 à 3,24]), qui habitaient dans l'épicentre de la consommation de drogue des quartiers pauvres (RCr 3,19 [95\% IC 1,78 à 5,73]) ou qui consommaient des drogues injectables (RCr 2,00 [95 \% IC 1,19 à 3,34]) ou non injectables (RCr 1,95 [95 \% IC 1,00 à 3,78]) étaient plus susceptibles d'avoir récemment subi un test de dépistage du VHC, tandis que les participantes immigrantes (RCr 0,24 [95\% IC 0,12 à 0,48]) l'étaient moins.

CONCLUSIONS : Malgré le fardeau élevé du VHC chez les travailleuses du sexe, d'importantes lacunes persistent dans le continuum des soins du VHC. Le faible accès au test de dépistage du VHC est particulièrement préoccupant, puisque le cinquième des femmes atteintes ne se savait pas infectées. La prévalence exceptionnellement faible de traitement du VHC est tout aussi préoccupante. Il est urgent de poursuivre les recherches pour mieux comprendre et vaincre les obstacles à la participation des travailleuses du sexe au continuum des soins du VHC.

\footnotetext{
Chronic hepatitis $\mathrm{C}$ virus (HCV) infection is an emerging global health problem. According to recent estimates, >185 million individuals worldwide are living with chronic HCV infection (1). Without treatment, between $15 \%$ and $30 \%$ of individuals with HCV will progress to cirrhosis, end-stage liver disease, hepatocellular carcinoma and, eventually, death. In fact, HCV is believed to be responsible for 350,000 annual deaths globally (1). HCV infection accounts not only for an important health and social burden (2), but also for a significant economic burden, both for the health system (3-5) and for the affected individual (6). Importantly, the economic burden of HCV is heavily associated with the treatment of complications associated with
}

end-stage liver disease (eg, cirrhosis, hepatocellular carcinoma), while viral clearance (ie, sustained virological response [SVR]) has been associated with lower costs $(5,7,8)$.

The burden of chronic HCV infection is also substantial in Canada, with approximately $0.8 \%$ of the Canadian population - nearly 250,000 individuals - living with HCV in 2007 (9,10). However, this figure is likely to be an underestimate of the real prevalence, which could be up to $2.8 \%(11,12)$. Chronic HCV is the leading indication for liver transplantation (13), and modelling studies have projected that, under the current status quo scenario, the incidence of HCV-related complications will continue to rise until at least $2035(5,10)$. In fact, a recent

${ }^{1}$ British Columbia Centre for Excellence in HIV/AIDS, St Paul's Hospital; ${ }^{2}$ Interdisciplinary Studies Graduate Program; ${ }^{3}$ Department of Medicine;

${ }^{4}$ School of Population and Public Health, University of British Columbia, Vancouver; ${ }^{5}$ Faculty of Health Sciences, Simon Fraser University, Burnaby,

British Columbia

Correspondence: Dr Kate Shannon, Department of Medicine, University of British Columbia, St Paul's Hospital, 608-1081 Burrard Street, Vancouver,

British Columbia V6Z 1Y6. Telephone 604-804-9459, fax 604-806-9044, e-mail gshi@cfenet.ubc.ca

Received for publication September 25, 2015. Accepted October 2, 2015 


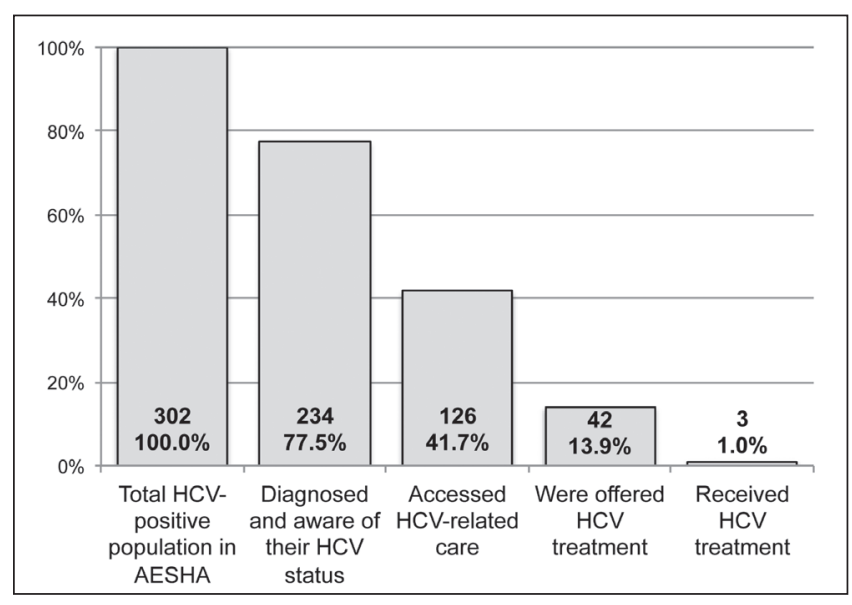

Figure 1) Hepatitis $\mathrm{C}$ virus (HCV) continuum of care for women sex workers living with HCV, Vancouver, British Columbia (n=302). AESHA An Evaluation of Sex Workers' Health Access

study from Ontario (2) found HCV to be the infectious disease accounting for the greatest loss of health-adjusted life years in the province.

Recent advances in HCV therapeutics have resulted in high success rates for all genotypes ( $>90 \%$ to $95 \%$ in most scenarios). Newer treatments are markedly more effective, safer, shorter and better tolerated (1). Importantly, HCV eradication is associated with up to $90 \%$ reductions in all-cause mortality, risk for developing hepatocellular carcinoma and need for liver transplantation (14). Additionally, achieving an SVR has a secondary prevention benefit, by eliminating the risk of onward transmission of $\mathrm{HCV}(15,16)$. In fact, given increasing availability of highly curative HCV drugs, and building on lessons from the HIV field (17), there have been increasing global calls to consider the implementation of HCV treatment as a prevention strategy $(15,16)$. However, this needs to be tempered by the potential for HCV reinfection.

A comprehensive HCV treatment and prevention strategy would need to meet several criteria to achieve optimal individual- and population-level health outcomes (18). Knowledge of HCV status (ie, being tested for and diagnosed with HCV) represents a critical first step in the HCV cascade of care. However, a substantial proportion of individuals living with HCV (at least $21 \%$ in Canada) remain unaware of their HCV status $(10,19)$ and are not connected to care and treatment; consequently, they are at risk for poor health outcomes. Collectively, these issues highlight the critical importance of access to and uptake of $\mathrm{HCV}$ treatment, as well as other prevention strategies, particularly among key affected populations, to maximize the impact of HCV efforts.

HCV disproportionally affects groups who are under-represented in health surveillance and who are underserved by the health system. Sex workers, particularly those who are street involved and use injection drugs, may be particularly vulnerable to HCV infection $(1,20)$. In addition, multiple studies show that sex workers face many unique challenges that can severely reduce their access to and uptake of health services. These include fear of disclosing sex work or drug use due to criminalization and stigmatization, disrespect from health care providers, poor quality of care, and lack of women- and sex worker-tailored services, among others $(21,22)$. However, and despite the increased vulnerability to HCV through dual sex/drug use routes and barriers to health services among sex workers, research examining access to HCV testing and care among this population remains negligible. Therefore, the aim of the current study was to characterize engagement in the HCV continuum of care and identify correlates of recent HCV testing among a cohort of women sex workers in metropolitan Vancouver, British Columbia.

\section{Study design}

\section{METHODS}

Data were drawn from An Evaluation of Sex Workers' Health Access (AESHA), an ongoing open prospective cohort of $>720$ women sex workers in metropolitan Vancouver, British Columbia, initiated in
2010. This study was developed based on community collaborations with sex work agencies since 2005 (23) and is monitored by a Community Advisory Board encompassing $>15$ agencies. Eligibility criteria for this cohort include age $\geq 14$ years, self-identification as women (including male-to-female transgender individuals), and having exchanged money for sex in the previous 30 days. Participants are recruited through a combination of outreach to outdoor/public (eg, streets, alleys), indoor (eg, massage parlours, microbrothels, in-call locations) and off-street (eg, online and newspapers advertisements) sex work venues across metropolitan Vancouver, using time-location sampling $(24,25)$. Sampling and recruitment procedures have been described in detail previously (23).

After providing written informed consent, participants complete an interview-administered questionnaire at baseline and every six months thereafter, and are offered HIV, HCV and other sexually transmitted infections testing, alongside pre- and post-test counselling. The questionnaire collects sociodemographic information, sex work patterns, sexual health and intimate partners, violence and trauma, drug use patterns, health care services access and utilization (including HIV and HCV care), and physical, social and structural characteristics of the working and living environment. A trained nurse provides basic treatment for sexually transmitted infections onsite, as well as referrals to health care services when needed. Participants receive an honorarium of $\$ 40$ at each visit for their time and expertise. The study has been approved by the Providence Health Care/University of British Columbia Research Ethics Board.

The current study used cross-sectional baseline data from participants who enrolled between January 2010 and August 2013.

\section{HCV continuum of care}

Study population: For the analysis characterizing the HCV continuum of care, only participants with serologically confirmed HCV infection (ie, HCV antibody positive) at baseline were included.

Statistical analysis: Descriptive statistics were used to assess engagement in each step of the HCV continuum of care, including the proportion of: women living with $\mathrm{HCV}$; diagnosed and aware of their infection; access to HCV related-care; offered treatment; and received treatment. Access to HCV care was evaluated through several questions regarding $\mathrm{HCV}$ care in the six months before the baseline visit, including whether women had received regular blood tests for HCV, had seen an HCV specialist, had been offered HCV treatment (including if declined) and had been receiving HCV treatment. The total number of HCV antibody-positive participants at baseline was used as the denominator for all calculations.

\section{Recent HCV testing}

Study population: The analysis of correlates of recent HCV testing was restricted to sex workers who self-reported being HCV-seronegative at enrollment or who acquired $\mathrm{HCV}<1$ year before the date of their baseline visit.

Primary outcome: The primary outcome of interest for this particular analysis was recent $\mathrm{HCV}$ testing, defined as self-reporting having tested for HCV within the 12 months before the baseline visit. Participants who had never tested for HCV or those whose last test was $>12$ months were considered to not have a recent HCV test.

Explanatory variables: Based on previous studies examining correlates of uptake of HCV and HIV testing among sex workers and other vulnerable populations (26-32), a range of individual, contextual and social-structural explanatory variables were selected that were hypothesized to influence utilization of HCV testing in this particular setting. Individual-level factors examined included sociodemographic characteristics, and substance use behaviours including age (per year older), Aboriginal/Indigenous ancestry (including First Nations, Métis and Inuit peoples, yes versus no), international migration status (immigrant/migrant versus Canadian born), self-identification as sexual/gender minority (lesbian, gay, bisexual, transgender or two-spirit versus heterosexuals), baseline HIV status (positive versus negative), heavy alcohol drinking ( $>4$ drinks per day, yes versus no), and any 
noninjection or injection drug use (yes versus no). Contextual factors evaluated included: current place of residence (residing in the inner city drug use epicentre [downtown eastside [DTES] versus elsewhere in Vancouver versus being homeless), physical and social features of the work environment such as primary place of soliciting clients (street/public place versus others, including off-street independent/ self-advertising or off-street indoor venue-based solicitation), servicing a higher number of clients ( $\geq 10$ versus $<10$ clients/week), inconsistent condom use with clients (defined as 'usually', 'sometimes', 'occasionally' or 'never' versus 'always'), client-perpetrated physical or sexual violence (yes versus no), involvement in peer support (yes versus no) and recent incarceration, defined as having been in detention, prison or jail overnight or longer (yes versus no). Also considered were socialstructural barriers to health services, including limited availability (defined as limited hours of operation or long wait times) and language barriers (yes versus no). Except for the sociodemographic variables, all other variables refer to the six-month period before the baseline visit. Statistical analysis: First, individual-, contextual- and social-structurallevel factors were compared among participants who self-reported undergoing a recent HCV test with those who did not. In the bivariate analyses, logistic regression was used to analyze the categorical and continuous variables. Then, to examine the independent factors associated with recent HCV testing, a multivariable logistic regression model was fitted using an a priori defined model-building approach based on the examination of the Akaike information criterion (AIC) and $\mathrm{P}$ values. A backward stepwise technique was used in the selection of covariates. This approach has been used successfully in several studies $(26,33)$. Starting with a full model containing all variables associated with the outcome at $\mathrm{P}<0.10$ level in bivariate analyses, the AIC of the model is noted and the variable with the largest $\mathrm{P}$ value is dropped to build a reduced model. This iterative process is continued until no variables are left. The model with the lowest AIC value is selected as the final model. Two-sided $\mathrm{P}$ values, and unadjusted and adjusted ORs (aOR) with 95\% CIs are reported. All statistical analyses were performed using SAS version 9.4 (SAS Institute, USA).

\section{$\mathrm{HCV}$ continuum of care}

\section{RESULTS}

Among 705 sex workers who received HCV testing at baseline, 302 were seropositive for $\mathrm{HCV}$, corresponding to an $\mathrm{HCV}$ prevalence of $42.8 \%$. Among them, the median age was 36 years (interquartile range 29 to 43 years), slightly more than one-half (51.7\%) were of Indigenous/Aboriginal ancestry, and one-third identified as a sexual/ gender minority $(33.1 \%)$. Recent use of noninjection or injection drugs was self-reported by $93.1 \%$ and $74.5 \%$, respectively. With regard to the work environment, the majority $(77.8 \%)$ were women who primarily solicited clients in public spaces. Overall, at baseline, $77.5 \%$ of participants were aware of their HCV infection, $41.7 \%$ reported having accessed HCV-related care, $13.9 \%$ having been offered treatment and only 1.0\% reported receiving treatment (Figure 1).

\section{Recent HCV testing}

The present analysis included 552 women sex workers, of whom 420 (76.1\%) self-reported being HCV-seronegative at baseline and an additional 132 (23.9\%) being newly diagnosed with HCV within one year before enrollment. The median age was 34 years (interquartile range 27 to 42 years), 183 (33.2\%) were of Indigenous/Aboriginal ancestry, and $46(8.3 \%)$ were also living with HIV. More than onequarter $(27.0 \%)$ lived in the inner city drug use epicentre, and more than one-half primarily solicited clients in public/outdoor settings $(51.6 \%)$. Recent use of noninjection or injection drugs was self-reported by $65.6 \%$ and $34.4 \%$ participants, respectively. In total, $292(52.9 \%)$ reported undergoing a recent $\mathrm{HCV}$ test (ie, within the past year).

As shown in Table 1 , factors positively and statistically significantly (ie, $\mathrm{P}<0.05$ ) associated with recent $\mathrm{HCV}$ testing in bivariate analyses included being of Aboriginal/Indigenous ancestry, identifying as a sexual/ gender minority, living with HIV, use of injection and noninjection

\section{TABLE 1}

Bivariate logistic regression analyses of factors associated with recent hepatitis $\mathrm{C}$ virus (HCV) testing among selfreported HCV-negative female sex workers in Vancouver, British Columbia $(n=552)$

\begin{tabular}{|c|c|c|c|c|}
\hline \multirow[b]{2}{*}{ Characteristic } & \multicolumn{2}{|c|}{ Recent HCV test, n (\%) } & \multirow[b]{2}{*}{ OR (95\% Cl) } & \multirow[b]{2}{*}{$\mathbf{P}$} \\
\hline & Yes $(n=292)$ & No $(n=260)$ & & \\
\hline Age, median (IQR) & $32.5(26-41)$ & $35(29-42)$ & $0.98(0.97-1.00)$ & 0.079 \\
\hline \multicolumn{5}{|c|}{ Sexual/gender minority } \\
\hline Yes & $99(33.9)$ & $33(12.7)$ & $3.53(2.28-5.47)$ & $<0.001$ \\
\hline No & $193(66.1)$ & $227(87.3)$ & & \\
\hline \multicolumn{5}{|l|}{ Aboriginal ancestry } \\
\hline Yes & $129(44.2)$ & $54(20.8)$ & $3.02(2.07-4.41)$ & $<0.001$ \\
\hline No & $163(55.8)$ & $206(79.2)$ & & \\
\hline \multicolumn{5}{|l|}{ Living with $\mathrm{HIV}^{*}$} \\
\hline Yes & $34(11.6)$ & $12(4.6)$ & $2.67(1.35-5.27)$ & 0.005 \\
\hline No & $257(88.0)$ & $242(93.1)$ & & \\
\hline \multicolumn{5}{|l|}{ Heavy drinking* } \\
\hline Yes & $9(3.1)$ & $4(1.5)$ & $2.02(0.61-6.63)$ & 0.248 \\
\hline No & $282(96.6)$ & $253(97.3)$ & & \\
\hline \multicolumn{5}{|c|}{ Non-injection drug use ${ }^{*}$} \\
\hline Yes & $254(87.0)$ & $108(41.5)$ & $9.41(6.18-14.33)$ & $<0.001$ \\
\hline No & $38(13.0)$ & $152(58.5)$ & & \\
\hline \multicolumn{5}{|l|}{ Injection drug use* } \\
\hline Yes & $149(51.0)$ & $41(15.8)$ & $5.57(3.71-8.34)$ & $<0.001$ \\
\hline No & $143(49.0)$ & $219(84.2)$ & & \\
\hline \multicolumn{5}{|c|}{ Immigrant to Canada } \\
\hline Yes & $25(8.6)$ & $142(54.6)$ & $0.08(0.05-0.13)$ & $<0.001$ \\
\hline No & $266(91.1)$ & $118(45.4)$ & & \\
\hline \multicolumn{5}{|c|}{ Current place of residence* (Vancouver, British Columbia) } \\
\hline Outside DTES & $134(45.9)$ & $210(80.8)$ & Reference & \\
\hline DTES & $125(42.8)$ & $24(9.2)$ & $8.16(5.01-13.29)$ & $<0.001$ \\
\hline Homelessness & $29(9.9)$ & $21(8.1)$ & $2.16(1.19-3.95)$ & 0.012 \\
\hline \multicolumn{5}{|c|}{ Primary place of soliciting clients* } \\
\hline Outdoor/public & $199(68.2)$ & $86(33.1)$ & $4.33(3.03-6.19)$ & $<0.001$ \\
\hline $\begin{array}{l}\text { Indoor/ off-street/ } \\
\text { independent }\end{array}$ & $93(31.8)$ & $174(66.9)$ & & \\
\hline \multicolumn{5}{|c|}{ Higher number of clients* } \\
\hline Yes ( $\geq 10 /$ week) & $140(48.0)$ & $148(56.9)$ & $0.69(0.49-0.97)$ & 0.035 \\
\hline No (<10/week) & $146(50.0)$ & $107(41.2)$ & & \\
\hline \multicolumn{5}{|c|}{ Inconsistent condom use with clients ${ }^{*}$} \\
\hline Yes & $65(22.3)$ & $31(11.9)$ & $2.16(1.36-3.45)$ & 0.001 \\
\hline No & $219(75.0)$ & $226(86.9)$ & & \\
\hline \multicolumn{5}{|c|}{ Involvement in peer support* } \\
\hline Yes & $53(18.2)$ & $22(8.5)$ & $2.47(1.46-4.20)$ & 0.001 \\
\hline No & $231(79.1)$ & $237(91.2)$ & & \\
\hline \multicolumn{5}{|c|}{ Physical/sexual violence by client* } \\
\hline Yes & $84(28.8)$ & $46(17.7)$ & $1.88(1.25-2.82)$ & 0.002 \\
\hline No & $208(71.2)$ & $214(82.3)$ & & \\
\hline \multicolumn{5}{|c|}{ Recent incarceration* } \\
\hline Yes & $57(19.5)$ & $19(7.3)$ & $3.11(1.79-5.38)$ & $<0.001$ \\
\hline No & $229(78.4)$ & $237(91.2)$ & & \\
\hline \multicolumn{5}{|c|}{ Language barrier to health services* } \\
\hline Yes & $3(1.0)$ & $29(11.2)$ & $0.08(0.03-0.28)$ & $<0.001$ \\
\hline No & $289(99.0)$ & $231(88.8)$ & & \\
\hline \multicolumn{5}{|c|}{ Availability barrier to health services* } \\
\hline Yes & $112(38.4)$ & $106(40.8)$ & $0.90(0.64-1.27)$ & 0.563 \\
\hline No & $180(61.6)$ & $154(59.2)$ & & \\
\hline
\end{tabular}

${ }^{*}$ Refers to the six-month period before the baseline interview. Column percentages may not necessarily sum to $100 \%$ due to missing data or rounding error. DTES Downtown eastside; IQR Interquartile range 


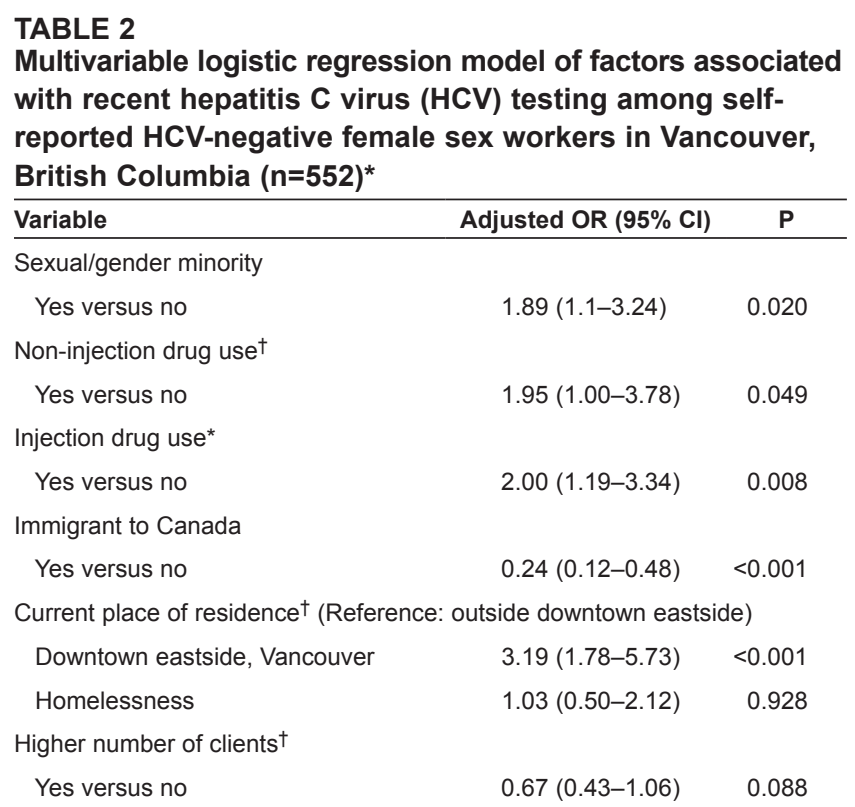

Recent incarceration ${ }^{\dagger}$

$\begin{array}{lll}\text { Yes versus no } & 1.87(0.95-3.67) & 0.069\end{array}$

*Only the final list of variables included in the model with the best overall fit (ie, lowest Akaike information criterion value) are shown. Age, Aboriginal ancestry, HIV status, primary place of soliciting clients, client-perpetrated violence, inconsistent condom use by clients, peer support and language barriers to health services were included in the full model, but removed in the backwards selection approach; ${ }^{\dagger}$ Refers to the six-month period before the baseline interview

drugs, currently residing in the inner city drug use epicentre, or being homeless (versus living outside the DTES), primarily soliciting clients in public/outdoor spaces, having been exposed to client-perpetrated violence, inconsistent condom use with clients, involvement in peer support and recent incarceration. In contrast, immigrant women, participants with higher number of clients and those reporting language barriers to health services had reduced odds of undergoing a recent HCV test.

As indicated in Table 2, in multivariable analyses, identifying as a sexual/gender minority (aAOR 1.89 [95\% CI 1.11 to 3.24]), use of injection (aOR 2.00 [95\% CI 1.19 to 3.34]) or noninjection drugs (aOR 1.95 [95\% CI 1.00 to 3.78]) and living in the inner city drug use epicentre (versus elsewhere in Vancouver) (aOR 3.19 [95\% CI 1.78 to 5.73]) remained independently and positively statistically significantly associated with undergoing a recent HCV test, while immigrant participants (aOR 0.24 [95\% CI 0.12 to 0.48$]$ ) were less likely to have had a recent $\mathrm{HCV}$ test.

\section{DISCUSSION}

To our knowledge, the present study was the first to characterize access and uptake along the HCV care continuum among sex workers, a population with disproportionate burden of $\operatorname{HCV}(1,20)$. In the present analysis, only one-half of the women who self-reported being HCV seronegative or previously unaware of their HCV status had been tested for $\mathrm{HCV}$ in the past year. In addition, among women living with $\mathrm{HCV}$, approximately one-quarter were unaware of their HCV status before undergoing an HCV test at their baseline visit. Importantly, and similar to a previous study of recent HIV testing among women sex workers in this setting (26), we found that a number of markers of vulnerability were associated with recent $\mathrm{HCV}$ testing, including use of noninjection and injection drugs, self-identification as a gender/ sexual minority, and living in the inner city drug use epicentre (ie, the DTES). In contrast, immigrant participants had reduced odds of undergoing a recent HCV test.
A possible explanation to our findings is that to date, voluntary HCV screening programs in Canada have mostly used a risk-based approach, targeting individuals perceived to be at higher risk for HCV infection, including people who use injection drugs, or with clinical or laboratory evidence of liver disease (9). It is likely that the provincial government-sponsored "HIV Treatment as Prevention" efforts (ie, STOP HIV/AIDS ${ }^{\circledR}$ ) to scale-up access to HIV testing and care, with a particular focus on the inner city DTES community, have contributed to increase uptake of HCV testing among these vulnerable populations $(34,35)$. However, the high prevalence of undiagnosed HCV infection among sex workers found in the present analysis suggests that the effectiveness of risk-based testing strategies for HCV may be limited. Studies suggest that years of targeted screening programs for HCV might have contributed to community or health provider perceptions that only certain vulnerable populations are at-risk of acquiring $\mathrm{HCV}$ (eg, people who inject drugs) $(36,37)$. Thus, given that HCV testing is only performed nominally, this stigma, as well as fear of disclosure of positive results, might pose barriers to HCV testing particularly in more underserved and criminalized populations such as women sex workers.

Of particular concern is that in our study, immigrant women were less likely to report having a recent HCV test. These results are consistent with previous research from different settings showing that migrant and new immigrant populations frequently experience enhanced barriers to health services $(33,38-40)$. These barriers include limited knowledge on how to navigate the local health system, stigma, cultural and language barriers, as well as woman's immigration legal status, which could result in exclusion from publicly funded health insurance. Altogether, these findings highlight the need for tailored interventions to facilitate migrant sex workers' access to voluntary testing and other health services, such as peer/sex worker-led outreach to connect migrant sex workers to culturally appropriate and low-threshold health services. In addition, as lessons from successful global initiatives demonstrate, community empowerment through sex workers collectivization can play a key role in increasing access to health and social services for all sex workers, including migrant women (41-43).

Our results also showed that $>40 \%$ of women sex workers in Vancouver had evidence of current/past HCV infection, likely due to dual parenteral and sexual routes (44-47). However, and despite this high HCV prevalence, fewer than one-half of sex workers living with $\mathrm{HCV}$ in our study reported being connected to HCV care and almost none were receiving treatment. These results are consistent with previous studies showing extremely low rates of $\mathrm{HCV}$ treatment uptake in British Columbia, particularly among women (4) and people who use illicit drugs (48).

Although not formally evaluated in the current study, determinants of low treatment uptake among this cohort of sex workers may reflect a combination of structural and individual barriers to health care. Misperceptions of HCV as relatively benign disease, absence of symptoms associated with chronic HCV until advanced stages, fear of side effects and associated treatment costs have been suggested as important individual-level barriers to HCV treatment uptake $(49,50)$. For example, a recent study indicated that individuals with chronic $\mathrm{HCV}$ in British Columbia face substantial out-of-pocket expenses on HCV-related health care, even within a publicly funded universal health care system. The burden of these costs mostly falls on individuals with lower income, which could play a key role in patients forgoing or delaying treatment until advances stages of liver diseases (6). Collectively, these findings suggest an urgent need to explore alternative mechanisms to facilitate and support engagement in care and to ensure equitable access to $\mathrm{HCV}$ treatment to vulnerable populations including sex workers $(4,6)$.

At the provider and macrostructural level, studies have demonstrated that stigma and misconceptions among health care providers regarding eligibility for $\mathrm{HCV}$ treatment of people who use drugs, as well as their perception of the clients potential to adhere to the regimen and 
eventual risk of re-infection represent major barriers to access to HCV treatment in this setting $(49,51,52)$. Additionally, Canada's criminalized sex work and drug use environment poses a further challenge in this regard. In fact, previous studies have shown that policing practices can play an important role in shaping health care access among marginalized populations such as sex workers, people who use drugs or transwomen (22,53-55). Accordingly, decriminalization of sex work and drug use could offer an important first step toward increasing access to HCV testing and care to these vulnerable populations and a critical step for the success of any HCV 'treatment as prevention' strategy $(16,56)$. For example, decriminalization of sex work could facilitate connections to health services of hidden migrant sex workers, who primarily work in indoor settings, do not disclose their involvement in sex work to friends, families and providers, and who are often disengaged from care. In addition, improving access to $\mathrm{HCV}$ care will require a combination intervention approach, including mobile and culturally competent services, as well as harm reduction and addiction management among other social-structural interventions (52).

The present study had several limitations. First, due its crosssectional design, we were unable to determine temporal and causal relationships between the explanatory variables and outcome. Second, our sample was not randomly selected and, therefore, the results of the present study may not be generalizable to all sex workers in Vancouver or to other settings. However, the use of time-location sampling $(24,25)$, a strategy known to help achieve representative samples of hard-to-reach populations helped to mitigate such potential bias. Third, because the data were collected through self-reporting, they may have been subject to recall or social-desirability biases. However, all interviews were conducted in confidential and safe environments by highly experienced interviewers with strong community rapport and involvement, facilitating accurate responses. Fourth, due to the lack of access to HCV RNA, we were not able to evaluate the number of participants with confirmed chronic HCV infection or with SVR. However, as studies of the natural history of HCV infection show, up to $85 \%$ of individuals infected with $\mathrm{HCV}$ will progress to chronic infection $(57,58)$. In addition, the extremely low $\mathrm{HCV}$ treatment uptake within this cohort makes SVR a rare event.

\section{SUMMARY}

Our results show that almost one-half of self-reported HCVseronegative women within a large cohort of women sex workers had not undergone an HCV test in the previous year, and hardly any women with HCV had accessed treatment. With increasing efficacy and tolerability of HCV drugs, these findings highlight the importance of facilitating and sustaining access to HCV testing, care and early treatment to all the population to improve not only individual and population outcomes, but also to decrease economic costs. In addition, given the high burden of HCV and large gaps in the HCV continuum of care among sex workers in Vancouver, future studies evaluating barriers and facilitators to HCV testing and care among this population are urgently needed to help inform public health efforts against HCV. Removal of criminal sanctions against sex work and drug use, as well as comprehensive interventions targeting these key populations, including mobile and culturally competent services, as well as harm reduction and addiction management will be critical to the success of any HCV treatment as a prevention strategy $(52,56)$.

ACKNOWLEDGEMENTS: The authors thank all those who contributed their time and expertise to this project, particularly participants, AESHA community advisory board members and partner agencies. We wish to acknowledge Chrissy Taylor, Jennifer Morris, Tina Ok, Rachel Nicoletto, Julia Homer, Emily Leake, Rachel Croy, Emily Groundwater, Meenakshi Mannoe, Silvia Machat, Jasmine McEachern, Brittany Udall, Chris Rzepa, Jungfei Zhang, Xin (Eleanor) Li, Krista Butler, Peter Vann, Sarah Allan and Jill Chettiar for their research and administrative support.
This research was supported by operating grants from the US National Institutes of Health (R01DA028648), the Canadian Institutes of Health Research (HHP-98835), the Canadian Institutes of Health Research/ Public Health Agency of Canada (HEB-330155), and MacAIDS. KS is partially supported by a Canada Research Chair in Global Sexual Health and HIV/AIDS and Michael Smith Foundation for Health Research. JSGM is supported with grants paid to his institution by the British Columbia Ministry of Health and by the US National Institutes of Health (R01DA036307). MES is a Canadian Institutes of Health Research Bridge Fellow.

DISCLOSURES: JSGM has received limited unrestricted funding, paid to his institution, from AbbVie, Bristol-Myers Squibb, Gilead Sciences, Janssen, Merck and ViiV Healthcare.

\section{REFERENCES}

1. Webster DP, Klenerman P, Dusheiko GM. Hepatitis C. Lancet 2015;385:1124-35.

2. Kwong JC, Ratnasingham S, Campitelli MA, et al. The impact of infection on population health: Results of the Ontario burden of infectious diseases study. PloS One2012;7:e44103.

3. El Saadany S, Coyle D, Giulivi A, Afzal M. Economic burden of hepatitis $\mathrm{C}$ in Canada and the potential impact of prevention. Results from a disease model. Eur J Health Econ 2005;6:159-65.

4. Hsu PC, Buxton JA, Tu AW, Hill WD, Yu A, Krajden M. Publicly funded pegylated interferon-alpha treatment in British Columbia: Disparities in treatment patterns for people with hepatitis C. Can J Gastroenterol 2008;22:359-64.

5. Myers RP, Krajden M, Bilodeau M, et al. Burden of disease and cost of chronic hepatitis C infection in Canada. Can J Gastroenterol Hepatol 2014;28:243-50.

6. Federico CA, Hsu PC, Krajden M, et al. Patient time costs and outof-pocket costs in hepatitis C. Liver Int 2012;32:815-25.

7. Backx M, Lewszuk A, White JR, et al. The cost of treatment failure: Resource use and costs incurred by hepatitis $\mathrm{C}$ virus genotype 1 -infected patients who do or do not achieve sustained virological response to therapy. J Viral Hepat 2014;21:208-15.

8. McEwan P, Ward T, Bennett H, et al. Estimating the clinical and economic benefit associated with incremental improvements in sustained virologic response in chronic hepatitis C. PloS One 2015;10:e0117334.

9. Shah HA, Heathcote J, Feld JJ. A Canadian screening program for hepatitis C: Is now the time? CMAJ 2013;185:1325-8.

10. Remis R. Modelling the incidence and prevalence of hepatitis C infection and its sequelae in Canada. Ottawa: Public Health Agency of Canada, 2007.

11. Uhanova J, Tate RB, Tataryn DJ, Minuk GY. A population-based study of the epidemiology of hepatitis $\mathrm{C}$ in a North American population. J Hepatol 2012;57:736-42.

12. Xeroulis G, Inaba K, Stewart TC, et al. Human immunodeficiency virus, hepatitis $\mathrm{B}$, and hepatitis $\mathrm{C}$ seroprevalence in a Canadian trauma population. J Trauma 2005;59:105-8.

13. Verna EC, Brown Jr RS. Hepatitis $\mathrm{C}$ virus and liver transplantation. Clin Liver Dis 2006;10:919-40.

14. Hill AM, Saleem J, Heath KA, Simmons B. Effects of sustained virological response (SVR) on the risk of liver transplant, hepatocellular carcinoma, death and re-infection: Meta-analysis of 129 studies in 23,309 patients with Hepatitis C infection. American Association for the Study of Liver Diseases (AASLD) Liver Meeting. Boston, November 7 to 11.

15. Grebely J, Matthews GV, Lloyd AR, Dore GJ. Elimination of hepatitis $\mathrm{C}$ virus infection among people who inject drugs through treatment as prevention: Feasibility and future requirements. Clin Infect Dis 2013;57:1014-20.

16. Martin NK, Vickerman P, Grebely J, et al. Hepatitis C virus treatment for prevention among people who inject drugs: Modeling treatment scale-up in the age of direct-acting antivirals. Hepatology 2013;58:1598-609.

17. Montaner JS, Hogg R, Wood E, et al. The case for expanding access to highly active antiretroviral therapy to curb the growth of the HIV epidemic. Lancet 2006;368:531-6.

18. Yehia BR, Schranz AJ, Umscheid CA, Lo Re V III. The treatment cascade for chronic hepatitis $\mathrm{C}$ virus infection in the United States: A systematic review and meta-analysis. PloS One 2014;9:e101554. 
19. Rein DB, Smith BD, Wittenborn JS, et al. The cost-effectiveness of birth-cohort screening for hepatitis C antibody in U.S. primary care settings. Ann Intern Med 2012;156:263-70.

20. Shannon K, Kerr T, Marshall B, et al. Survival sex work involvement as a primary risk factor for hepatitis $\mathrm{C}$ virus acquisition in drug-using youths in a Canadian setting. Arch Pediatr Adolesc Med 2010;164:61-5.

21. Scorgie F, Nakato D, Harper E, et al. 'We are despised in the hospitals': Sex workers' experiences of accessing health care in four African countries. Cult Health Sex 2013;15:450-65.

22. Shannon K, Rusch M, Shoveller J, et al. Mapping violence and policing as an environmental-structural barrier to health service and syringe availability among substance-using women in street-level sex work. Int J Drug Policy 2008;19:140-7.

23. Shannon K, Bright V, Allinott S, et al. Community-based HIV prevention research among substance-using women in survival sex work: The Maka Project Partnership. Harm Reduct J 2007;4:20.

24. Clark JL, Konda KA, Silva-Santisteban A, et al. Sampling methodologies for epidemiologic surveillance of men who have sex with men and transgender women in Latin America: An empiric comparison of convenience sampling, time space sampling, and respondent driven sampling. AIDS Behav 2014;18:2338-48.

25. Stueve A, O'Donnell LN, Duran R, San Doval A, Blome J. Timespace sampling in minority communities: Results with young Latino men who have sex with men. Am J Public Health 2001;91:922-6.

26. Deering KN, Montaner JS, Chettiar J, et al. Successes and gaps in uptake of regular, voluntary HIV testing for hidden street- and offstreet sex workers in Vancouver, Canada. AIDS Care 2014:1-8.

27. Hagan H, Campbell J, Thiede H, et al. Self-reported hepatitis C virus antibody status and risk behavior in young injectors. Public Health Rep 2006;121:710-9.

28. Kwiatkowski CF, Fortuin Corsi K, Booth RE. The association between knowledge of hepatitis $\mathrm{C}$ virus status and risk behaviors in injection drug users. Addiction 2002;97:1289-94.

29. Batona G, Gagnon MP, Simonyan DA, Guedou FA, Alary M. Understanding the intention to undergo regular HIV testing among female sex workers in Benin: A key issue for entry into HIV care. J Acquir Immune Defic Syndr 2015;68 Suppl 2:S206-12.

30. Xu J, Brown K, Ding G, et al. Factors associated with HIV testing history and HIV-test result follow-up among female sex workers in two cities in Yunnan, China. Sex Transm Dis 2011;38:89-95.

31. Wang Y, Li B, Pan J, Sengupta S, et al. Factors associated with utilization of a free HIV VCT clinic by female sex workers in Jinan City, Northern China. AIDS Behav 2011;15:702-10.

32. Surratt HL, O'Grady CL, Kurtz SP, Buttram ME, Levi-Minzi MA. HIV testing and engagement in care among highly vulnerable female sex workers: Implications for treatment as prevention models. J Health Care Poor Underserved 2014;25:1360-78.

33. Goldenberg SM, Liu V, Nguyen P, Chettiar J, Shannon K. International migration from non-endemic settings as a protective factor for HIV/STI risk among female sex workers in Vancouver, Canada. J Immigr Minor Health 2015;17:21-8.

34. O'Shaughnessy MV, Hogg RS, Strathdee SA, Montaner JS. Deadly public policy: What the future could hold for the HIV epidemic among injection drug users in Vancouver. Curr HIV/AIDS Rep 2012;9:394-400.

35. Heath K, Samji H, Nosyk B, et al. Cohort profile: Seek and treat for the optimal prevention of HIV/AIDS in British Columbia (STOP HIV/AIDS BC). Int J Epidemiol 2014;43:1073-81.

36. Barocas JA, Brennan MB, Hull SJ, Stokes S, Fangman JJ, Westergaard RP. Barriers and facilitators of hepatitis C screening among people who inject drugs: A multi-city, mixed-methods study. Harm Reduct J 2014;11:1.

37. Strauss SM, Munoz-Plaza C, Tiburcio NJ, et al. Barriers and facilitators to undergoing hepatitis $\mathrm{C}$ virus (HCV) testing through drug treatment programs. J Drug Issues 2008;38:1161-85.

38. Goldenberg SM, Chettiar J, Nguyen P, Dobrer S, Montaner J, Shannon K. Complexities of short-term mobility for sex work and migration among sex workers: Violence and sexual risks, barriers to care, and enhanced social and economic opportunities.

J Urban Health 2014;91:736-51.
39. Guirgis M, Nusair F, Bu YM, Yan K, Zekry AT. Barriers faced by migrants in accessing healthcare for viral hepatitis infection. Intern Med J 2012;42:491-6.

40. Richter M, Chersich MF, Vearey J, Sartorius B, Temmerman M, Luchters S. Migration status, work conditions and health utilization of female sex workers in three South African cities. J Immigr Minor Health 2014;16:7-17.

41. Beattie TS, Mohan HL, Bhattacharjee P, et al. Community mobilization and empowerment of female sex workers in Karnataka State, South India: Associations with HIV and sexually transmitted infection risk. Am J Public Health 2014;104:1516-25.

42. Kerrigan DL, Fonner VA, Stromdahl S, Kennedy CE. Community empowerment among female sex workers is an effective HIV prevention intervention: A systematic review of the peer-reviewed evidence from low- and middle-income countries. AIDS Behav 2013;17:1926-40.

43. Parimi P, Mishra RM, Tucker S, Saggurti N. Mobilising community collectivisation among female sex workers to promote STI service utilisation from the government healthcare system in Andhra Pradesh, India. J Epidemiol Community Health 2012;66(Suppl 2):ii62-8.

44. Duff P, Tyndall M, Buxton J, Zhang R, Kerr T, Shannon K. Sex-forcrack exchanges: Associations with risky sexual and drug use niches in an urban Canadian city. Harm Reduct J 2013;10:29.

45. Shannon K, Rusch M, Morgan R, Oleson M, Kerr T, Tyndall MW. $\mathrm{HIV}$ and HCV prevalence and gender-specific risk profiles of crack cocaine smokers and dual users of injection drugs. Subst Use Misuse 2008;43:521-34

46. DeBeck K, Kerr T, Li K, et al. Smoking of crack cocaine as a risk factor for HIV infection among people who use injection drugs. CMAJ 2009; 181:585-9.

47. Nurutdinova D, Abdallah AB, Bradford S, O'Leary CC, Cottler LB. Risk factors associated with hepatitis $\mathrm{C}$ among female substance users enrolled in community-based HIV prevention studies. BMC Res Notes. 2011;4:126.

48. Grebely J, Raffa JD, Lai C, et al. Low uptake of treatment for hepatitis $\mathrm{C}$ virus infection in a large community-based study of inner city residents. J Viral Hepat 2009;16:352-8.

49. Bruggmann P. Accessing hepatitis $C$ patients who are difficult to reach: It is time to overcome barriers. J Viral Hepat 2012;19:829-35.

50. Grebely J, Genoway KA, Raffa JD, et al. Barriers associated with the treatment of hepatitis $C$ virus infection among illicit drug users. Drug Alcohol Depend 2008;93:141-7.

51. Myles A, Mugford GJ, Zhao J, Krahn M, Wang PP. Physicians' attitudes and practice toward treating injection drug users with hepatitis C: Results from a national specialist survey in Canada. Can J Gastroenterol 2011;25:135-9.

52. Harris M, Rhodes T. Hepatitis $C$ treatment access and uptake for people who inject drugs: A review mapping the role of social factors. Harm Reduct J 2013;10:7.

53. Kerr T, Hayashi K, Ti L, Kaplan K, Suwannawong P, Wood E. The impact of compulsory drug detention exposure on the avoidance of healthcare among injection drug users in Thailand. Int J Drug Policy 2014;25:171-4.

54. Socias ME, Marshall BD, Aristegui I, et al. Factors associated with healthcare avoidance among transgender women in Argentina. Int J Equity Health 2014;13:81.

55. Kerr T, Small W, Wood E. The public health and social impacts of drug market enforcement: A review of the evidence. Int J Drug Policy 2005;16:210-20.

56. Bruggmann P. Treatment as prevention: The breaking of taboos is required in the fight against hepatitis $\mathrm{C}$ among people who inject drugs. Hepatology 2013;58:1523-5.

57. Micallef JM, Kaldor JM, Dore GJ. Spontaneous viral clearance following acute hepatitis $\mathrm{C}$ infection: A systematic review of longitudinal studies. J Viral Hepat 2006;13:34-41.

58. Thomson EC, Fleming VM, Main J, et al. Predicting spontaneous clearance of acute hepatitis $\mathrm{C}$ virus in a large cohort of HIV-1-infected men. Gut 2011;60:837-45. 


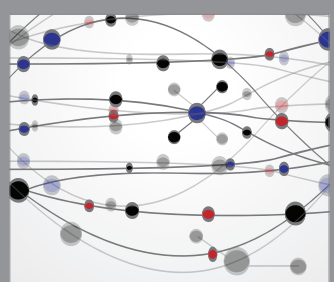

The Scientific World Journal
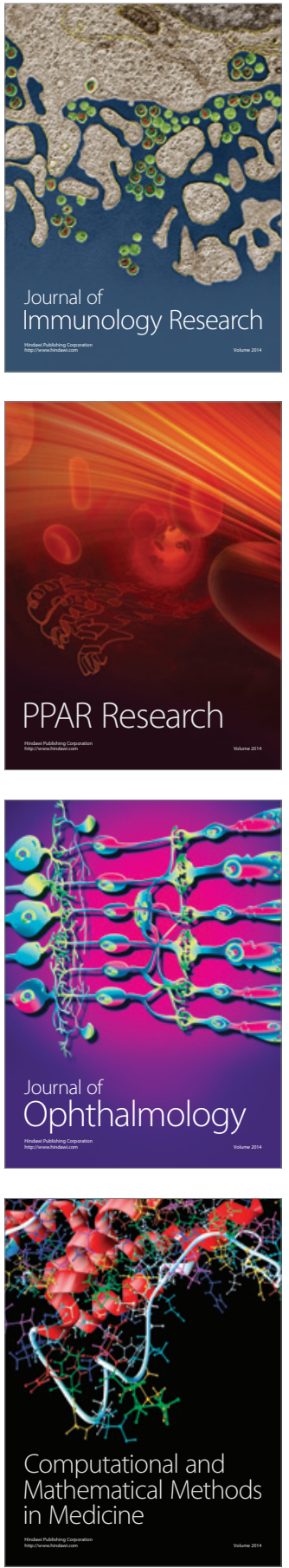

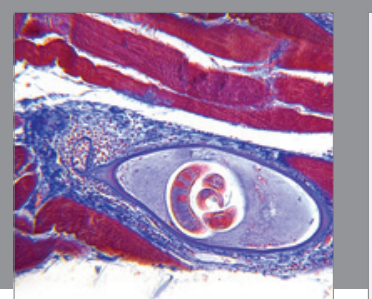

Gastroenterology Research and Practice

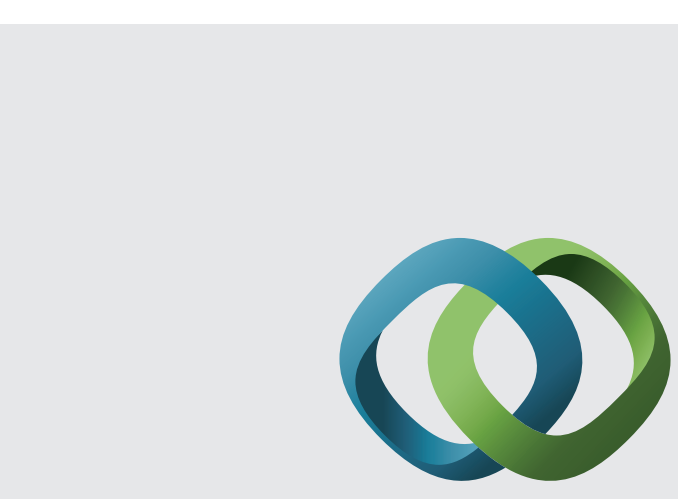

\section{Hindawi}

Submit your manuscripts at

http://www.hindawi.com
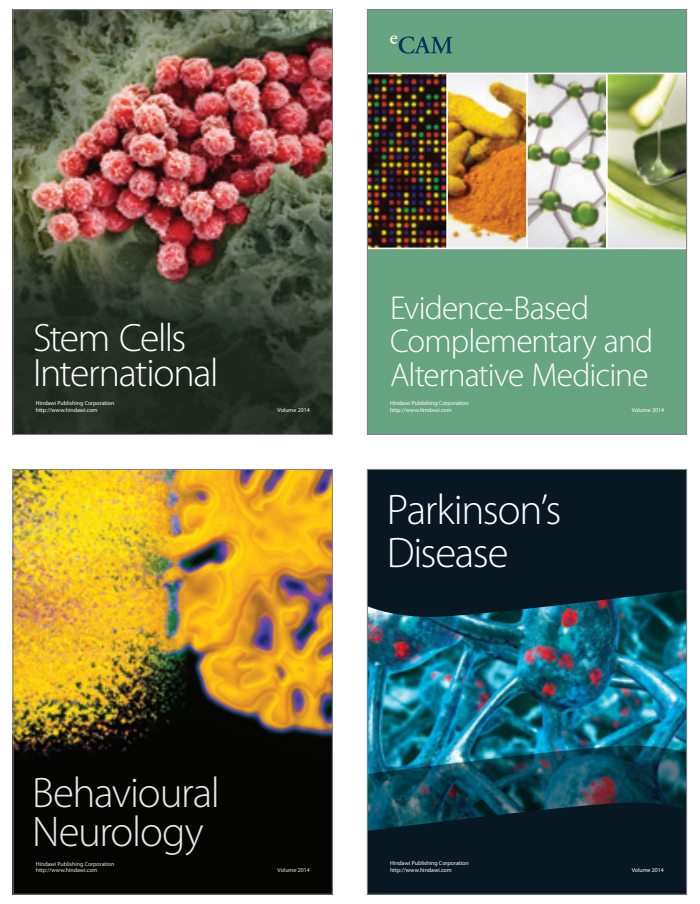
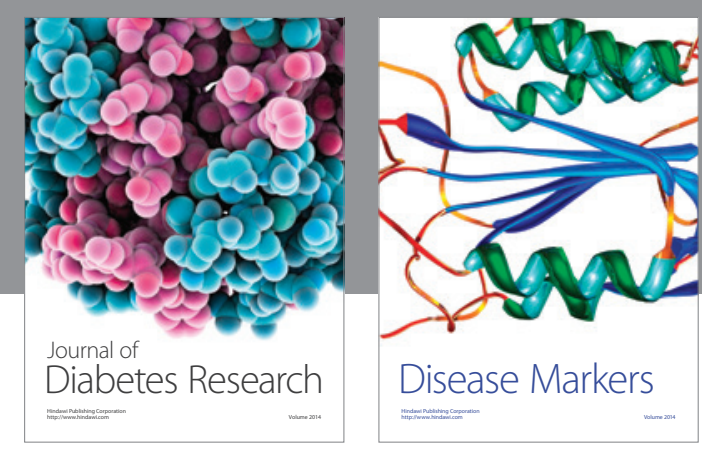

Disease Markers
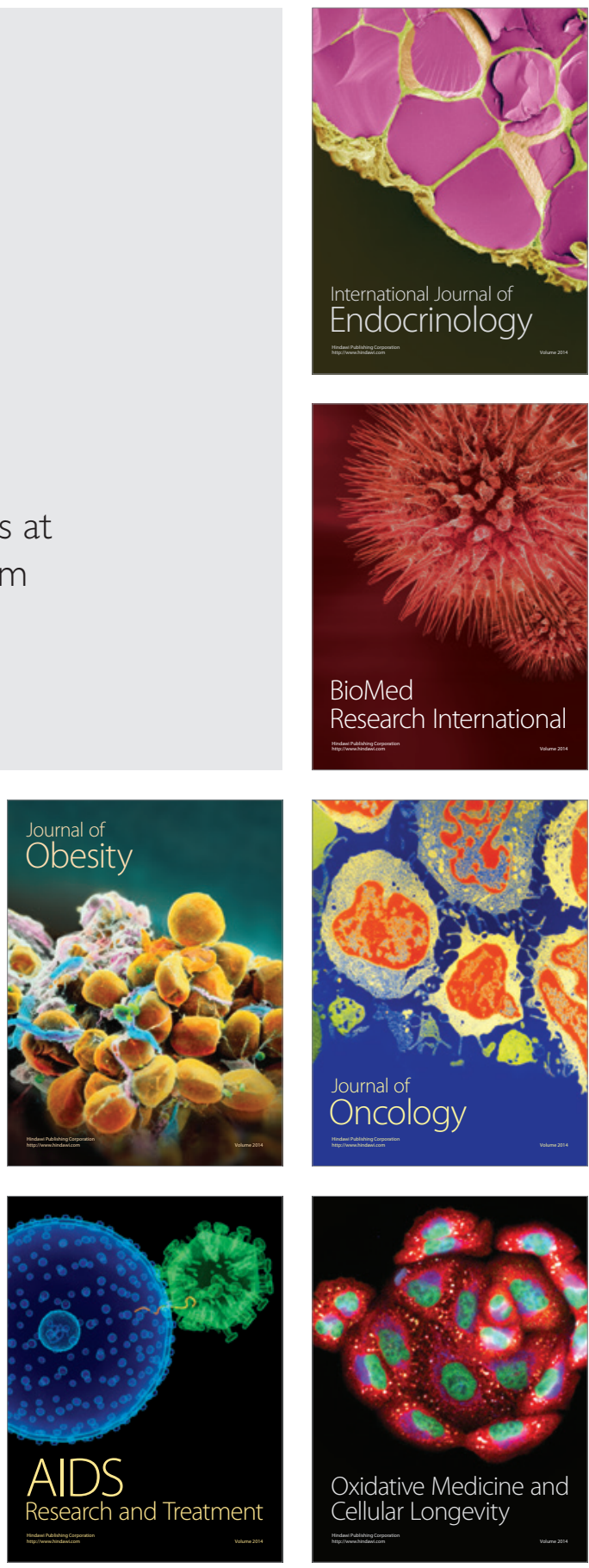